Camila Ferreira da Silva

Universidade Federal do Amazonas, UFAM

E-mail: cfsilva@ufam.edu.br

Dhttp://orcid.org/0000-0002-2348-9350

\section{A seção de sociologia da educação da associação portuguesa de sociologia: autorreflexão e reverberações teórico- metodológicas}

\section{Camila Ferreira da Silva}

\section{Resumo}

Tomar a Sociologia da Educação como objeto de análise, no contexto português, significa reconhecer o terreno histórico e social no qual seu desenvolvimento encontrou condições de possibilidade. Alguns trabalhos pioneiros ainda na década de 1960, sua inserção no ensino superior somente após o fim do regime autoritário em 1974, bem como seu processo de construção e consolidação enquanto campo relativamente autônomo levam-nos hoje a interrogar diferentes espaços de socialização e discussão da produção em Sociologia da Educação nesse país. A partir disso, o presente artigo pretende analisar um desses espaços, a Seção de Sociologia da Educação da Associação Portuguesa de Sociologia (APS), em duas frentes complementares: seus exercícios de autorreflexão e suas marcas teórico-metodológicas. Com base na Sociologia Compreensiva, na combinação entre as abordagens quanti e qualitativa (mixed methods) e no diálogo com o pensamento bourdieusiano no âmbito de seus constructos sobre o campo científico, as newsletters $\mathrm{e}$ as atas dos congressos organizados pela supracitada seção constituem, pois, as fontes de que este estudo se ocupa. Questionamentos em torno da seção aqui apreciada, de seus pesquisadores associados, bem como das suas principais preocupações e discussões, da agenda de pesquisa e especialmente do quadro teórico e metodológico que tem se desenhado no cenário recente ganham centralidade neste texto e, ao passo que são aprofundados por meio da apresentação e discussão dos dados e dos achados do estudo, acabam por revelar os caminhos que a Sociologia da Educação tem percorrido no contexto português na última década.

Palavras-chave: Sociologia da Educação. Associação Portuguesa de Sociologia. Portugal.. 
Abstract

\section{Keywords:}

Sociology of

Education.

Portuguese

Association of

Sociology. Portugal.

\section{Resumen}

\author{
Palabras clave: \\ Sociología de la \\ Educación. \\ Asociación \\ Portuguesa de \\ Sociología. \\ Portugal..
} The Sociology of Education Section of the Portuguese Sociology Association: self-
reflection and theoretical-methodological reverberations

Taking the Sociology of Education for analysis, in the Portuguese context, means recognizing the historical and social terrain in which its development found conditions of possibility. Some pioneering work still in the 1960 s, its insertion in higher education only after the end of the authoritarian regime in 1974, as well as its process of construction and consolidation as a relatively autonomous field, leads us today to question different spaces of socialization and discussion of production in Sociology of Education in this country. Based on this, the present article intends to analyze one of these spaces, the Sociology of Education Section of the Portuguese Association of Sociology (APS), on two complementary fronts: its self-reflection exercises and its theoretical-methodological marks. Based on Comprehensive Sociology, the combination of quantitative and qualitative approaches (mixed methods) and dialogue with Bourdieusian thought in the context of its constructs on the scientific field, the newsletters and minutes of the congresses organized by the aforementioned section constitute, therefore, the sources that this study deals with. Questions about the section discussed here, its associated researchers, as well as their main concerns and discussions, the research agenda and especially the theoretical and methodological framework that has been drawn in the recent scenario, gain centrality in this text and, while they are deepened through the presentation and discussion of the data and findings of the study, they end up revealing the paths that Sociology of Education has taken in the Portuguese context in the last decade.

La Sección de Sociología de la Educación de la Asociación Portuguesa de Sociología: autorreflexión y reverberaciones teórico-metodológicas

Tomar la Sociología de la Educación para su análisis, en el contexto portugués, significa reconocer el terreno histórico y social en el que su desarrollo encontró condiciones de posibilidad. Algunos trabajos pioneros aún en la década de 1960, su inserción en la educación superior solo después del final del régimen autoritario en 1974, así como su proceso de construcción y consolidación como un campo relativamente autónomo, nos lleva a cuestionar diferentes espacios de socialización y discusión de la producción. en Sociología de la educación en este país. En base a esto, el presente artículo pretende analizar uno de estos espacios, la Sección de Sociología de la Educación de la Asociación Portuguesa de Socioalogía (APS), en dos frentes complementarios: sus ejercicios de autorreflexión y sus marcas teórico-metodológicas. Basado en la sociología integral, la combinación de enfoques cuantitativos y cualitativos (métodos mixtos) y el diálogo con el pensamiento bourdieusiano en el contexto de sus construcciones en el campo científico, los boletines y las actas de los congresos organizados por la sección mencionada constituyen, por lo tanto, fuentes que trata este estudio. Las preguntas sobre la sección discutida aquí, sus investigadores asociados, así como sus principales preocupaciones y discusiones, la agenda de investigación y especialmente el marco teórico y metodológico que se ha elaborado en el escenario reciente, ganan importancia en este texto y, mientras están profundizado a través de la presentación y discusión de los datos y hallazgos del estudio, terminan revelando los caminos que la Sociología de la Educación ha tomado en el contexto portugués en la última década.. 


\section{Introdução}

A Sociologia da Educação (SE) em Portugal constituiu-se como um espaço científico relativamente autônomo no cenário recente; embrionariamente, poderíamos trazer a década de 1960 como seu marco, em função da tônica depositada sobre a educação na discussão pública; mais sistematicamente, temos que tomar a década de 1980 como divisor de água para o processo de consolidação do espaço acadêmico específico da SE no país, o que esteve diretamente atrelado ao fim do regime autoritário em 1974. De modo geral, podemos afirmar que a SE portuguesa tem sua história de constituição atrelada à história da própria disciplina da Sociologia, bem como a um diálogo com diferentes áreas do conhecimento, no sentido do exercício de objetivar os fenômenos educacionais. As Ciências da Educação destacam-se nessa seara, em função de uma relação que foi se efetivando tanto no plano do ensino e da formação de professores quanto no plano da investigação e formação de pesquisadores (MACHADO, 2009; SILVA; ALVES, 2015; EGREJA, 2016).

A autorreflexão sobre a história e os caminhos que a Sociologia da Educação tem construído em Portugal não é um exercício inédito no país, visto que um número significativo de publicações, datadas do final da década de 1980 e que se renovam e complementam até os nossos dias, tem tomado como objeto de análise o ofício dos sociólogos da educação, aliando as agendas de investigação desenvolvidas ao longo do tempo às condições de desenvolvimento e consolidação do campo científico em questão. Caria (1995), já na década de 1990, destacava essa tendência de os pesquisadores que compõem o campo científico da SE portuguesa analisarem este mesmo espaço como um de seus traços marcantes, uma vez que o conjunto das iniciativas de autoanálise, nas palavras do autor, "[...] chama a atenção para o facto de provavelmente, em Portugal, a educação ser um dos campos de aplicação da Sociologia onde mais se problematizam os saberes construídos e a utilização social das Ciências Sociais" (CARIA, 1995, p. 1).

Vinte e cinco anos após a afirmação de Telmo Caria, é possível observar que este movimento reflexivo sobre a SE tem perdurado ao longo do tempo no cenário português. De modo geral, pode-se apontar algumas das principais frentes de análise que condensam este exercício, a saber: estado da disciplina (STOER; AFONSO, 1999; AFONSO, 2005); principais temáticas abordadas e tendências na pesquisa em SE (STOER; AFONSO, 1999; ABRANTES, 2010; SERPA, 2018); passado, presente e futuro da SE portuguesa (STOER, 1988, 1990, 2008; DIONÍSIO; TORRES; ALVES, 2018); e a relação entre Sociologia e Ciências da Educação no âmbito da Sociologia da Educação (CARIA, 1995; ABRANTES, 2004; SILVA; ALVES, 2015).

Todos esses trabalhos, apartados histórica e geograficamente, têm em comum o ponto de partida que motivou seus autores: a necessidade de compreender a Sociologia da Educação enquanto campo científico, disciplina ou área de ensino. Em síntese, o espaço acadêmico específico da SE foi sendo 
interrogado à medida que alcançava um número maior de agentes envolvidos no seu jogo científico (pesquisadores, professores e estudantes dos cursos de mestrado e doutoramento), bem como à medida em que se apresentava paulatinamente como uma esfera já consolidada no interior do cenário da ciência em Portugal.

O presente artigo situa-se, pois, nesta tradição de trabalhos que têm se colocado a tarefa de pensar as bases sobre as quais se desenvolve a SE portuguesa, pelo que tem como objetivo central analisar um dos principais espaços da SE no país, a Seção de Sociologia da Educação da Associação Portuguesa de Sociologia (APS). A seção em questão é aqui trazida à análise em duas frentes: seus exercícios de autorreflexão e suas marcas teóricos-metodológicas. Para tal, ancoramos nosso estudo na Sociologia Compreensiva e na combinação entre as abordagens quanti e qualitativa (mixed methods) e no diálogo com o pensamento de Pierre Bourdieu. As principais fontes de que este estudo se ocupa são as newsletters e as atas dos congressos/encontros organizados pela Seção de Sociologia da Educação da APS.

Tomando como fio condutor do artigo as principais marcas da SE portuguesa na atualidade, o texto é assinalado pelo seguinte movimento: em um primeiro momento, são apresentados os caminhos metodológicos do estudo, com vistas a situar o leitor quanto ao design adotado; em seguida, ocupamo-nos do exercício de compreender o papel da APS e de sua Seção Temática de Sociologia da Educação no cenário mais amplo do desenvolvimento da SE em Portugal. Não se trata de uma reconstrução histórica exaustiva em torno deste campo científico - o que já se encontra amplamente difundido na literatura especializada , mas sim da compreensão do que a criação e atuação desta seção significam para a SE neste país. Por fim, o último tópico do artigo traz a análise da seção supracitada e do corpus do estudo, momento em que o mapeamento e caracterização da agenda de pesquisa, dos referenciais teóricos e metodológicos presentes na Seção de Sociologia da Educação da APS são apresentados e perscrutados.

\section{Nota metodológica}

Para a construção do design do estudo que sustenta o presente artigo, foi preciso levar em consideração algumas questões preliminares, nomeadamente: a) a APS é uma das expressões da institucionalização da Sociologia no cenário português, o que nos leva a compreender as correlações entre a consolidação deste campo científico e a construção de seus espaços de formação, socialização e diálogo; b) a Seção de Sociologia da Educação da APS segue, pois, a mesma lógica institucionalizante e nos fala da capacidade associativa dos pesquisadores no âmbito da SE em Portugal, os quais, além dos cursos de licenciatura e de mestrado e doutoramento, passam também a construir novos espaços de socialização de conhecimento e de diálogo entre pares (tais como grupos de pesquisa, unidades de investigação, periódicos, fóruns, eventos científicos e a própria seção em questão). 
A compreensão do lugar e do papel da Seção de Sociologia da Educação da APS permitiu-nos tomála como objeto de análise com base na história da própria Sociologia portuguesa, a qual, no seu processo de consolidação, tem construído diferentes espaços de socialização e discussão da produção científica. Isso leva-nos a afirmar que o recorte empreendido metodologicamente neste estudo, que nos possibilitou objetivar a seção em questão, implicou a reafirmação de que a SE portuguesa não se reduz a um único espaço institucional, ela é exatamente o resultado do conjunto de agentes e de seus agrupamentos, instituições de ensino superior, de pesquisa e de fomento à investigação, além das produções resultantes do trabalho desses agentes (HEY, 2008).

Epistêmica e metodologicamente falando, o trabalho com este espaço da SE portuguesa, a Seção de Sociologia da Educação da APS, assentou-se na Sociologia Compreensiva, de perspectiva bourdieusiana os constructos de Pierre Bourdieu sobre o campo científico servem, pois, de principal referencial teórico para as categorizações e análises realizadas. Recorremos ainda à combinação entre as abordagens qualitativa e quantitativa, ou mixed methods (CRESWELL, 2012), para a mirada lançada ao corpus do estudo, o qual adveio diretamente das newsletters e das atas dos congressos organizados pela Seção de Sociologia da Educação da APS.

Todo material relativo às newsletters e às atas dos encontros desta seção foi levantado na própria página eletrônica da APS, ${ }^{1}$ a qual conta com um ambiente para cada uma de suas seções. Seguiram-se ao levantamento as etapas de leitura do material, construção dos dados, categorização e análise. Para tal, foram criadas estratégias próprias para cada tipo de informação com a qual lidamos. Como as newsletters foram ganhando estruturas diferentes ao longo dos anos, a categorização que empreendemos buscou mapear os principais elementos, temáticas e pesquisadores que figuram nas colunas, suas instituições de filiação, bem como as principais temáticas abordadas. Desse modo, este mapeamento nos fala acerca da agenda de discussão da SE em Portugal, bem como dos sujeitos engajados no projeto da seção estudada. Em complemento, as informações contidas nas atas dos congressos foram categorizadas de forma a possibilitar a leitura e análise das tendências temáticas e dos principais referenciais teóricos e metodológicos que marcaram esses eventos.

\section{A Sociologia da Educação em Portugal e o papel da APS}

A organização do campo científico tal como conhecemos hoje é fruto de processos históricos de lutas por legitimação em torno de projetos para este campo social. Dessa forma, nenhuma das propriedades de um campo científico é gerada aprioristicamente, elas possuem valor, então, somente neste universo de referência (BOURDIEU, 2003, 2008). Nesse sentido, objetivar um espaço no interior do campo científico, 
como se propõe neste tópico, significa enxergar este mesmo espaço como um dos elementos desta luta, que, no âmbito de nosso objeto de estudo, liga-se à história da consolidação da SE em Portugal.

Esses pressupostos nos possibilitam compreender a estruturação do campo científico português e, mais especificamente, dos espaços acadêmicos específicos da Sociologia e da SE. Se pensarmos na influência da Sociologia francesa (especialmente de Augusto Comte e Émile Durkheim) sobre a produção de intelectuais portugueses nas primeiras décadas do século XX, bem como na presença da Sociologia nos trabalhos sobre questões educacionais na década de 1960, e ainda nas implicações do fim do regime autoritário em abril de 1974 para o impulsionamento da SE no país, ficará evidente que o debate sociológico sobre a educação foi paulatinamente ganhando o espaço da universidade (AFONSO, 2001; STOER, 2008).

Notadamente, a literatura especializada aponta razões para, na história da Sociologia portuguesa, a educação ter se destacado como objeto ou tema de investigação, como elemento explicativo para objetos outros e como elemento crucial no debate público. Tais razões são reveladoras de movimentos que foram se agudizando no país nas décadas citadas anteriormente, tais como: a necessidade de melhorar os índices de escolarização do povo português; a urgência de compreender os fatores decisivos para a permanência na escola; a correlação entre desenvolvimento, modernização e educação/qualificação; as políticas públicas e reformas educacionais; e a crescente necessidade de formar professores e de pensar sobre esta formação. São esses movimentos, combinados com a expansão da comunidade científica, que servem de cenário para as condições de possibilidade de consolidação de uma SE em Portugal.

Com a institucionalização da SE portuguesa, sobretudo em espaços como as universidades, os centros de pesquisa ou as unidades de investigação, a sua consolidação passa a se expressar na ampliação de um corpo de professores, pesquisadores e estudantes que se dedicam a estudar e a construir conhecimento científico neste escopo. O estabelecimento de cadeiras dedicadas à SE nos cursos de Sociologia, Ciências da Educação e em algumas outras licenciaturas dedicadas a formar professores, bem como nos cursos de mestrado e doutoramento que possuem linhas de investigação direta ou indiretamente relacionadas à SE, são exemplos de sua presença no cenário acadêmico português e, naturalmente, de um corpo de docentes e pesquisadores especializados neste domínio.

A consolidação da Sociologia da Educação em Portugal, seguindo uma tendência mundial, significou também o estabelecimento de diálogos interinstitucionais e de redes de pesquisa nacionais e internacionais. De modo geral,

Criar e expandir o diálogo entre os agentes de uma determinada área do conhecimento é, pois, uma necessidade para o estabelecimento colaborativo de bases disciplinárias, de uma cultura de debate maduro acerca de correntes teóricas, paradigmas, objetos de pesquisa, temas de investigação [...] e também acerca da própria organização da área e das diretrizes a serem construídas e seguidas no sentido de fortalecer um espaço acadêmico específico. (SILVA, 2017, p. 122). 
Desse modo, é possível entender o estabelecimento de um diálogo de maior envergadura na SE portuguesa nas últimas décadas, ou seja, para além dos cursos de mestrado e doutoramento e mesmo das unidades de investigação, que naturalmente já aproximavam os pesquisadores no interior de uma mesma instituição. A circulação de toda a produção acadêmica nacional em SE acabou por promover uma espécie de integração dos agentes e dos bens culturais, que são produzidos, naturalmente, em contextos distintos e apartados geograficamente. $\mathrm{O}$ conceito de comunidade científica ou acadêmica - com todas as críticas ao termo (SOUZA, 2010), que geralmente são ligadas a uma espécie de 'denúncia' do romantismo que dele advém, ou ao descortinar de sua essência de lutas (BOURDIEU, 2008, 2011) - ganha sentido quando concebemos a rede de diálogos e cooperação que se constitui em torno das mais variadas formas de circulação da produção acadêmica de determinada área. Temos então, de fato, um grupo de agentes que atua na SE portuguesa, representa sua comunidade científica e, exatamente por isso, carrega consigo suas relações de colaboração e, igualmente, de luta.

O fim da ditadura salazarista permitiu uma autonomização madura da ciência em Portugal, acompanhada pela Sociologia e a SE, que as coloca diante, dentre outros, do desafio de refletir sobre si e estabelecer suas próprias bases disciplinares. Não seria exagero afirmar que, no contexto posterior à revolução democrática, a ciência, as mais diferentes áreas do conhecimento, as instituições ligadas à investigação e os pesquisadores tiveram que reinventar seus ofícios e seus respectivos campos de atuação. Nesse sentido, a reorganização de muitos cursos superiores, bem como as discussões em torno de seus currículos, a criação de cursos de mestrado e doutoramento e o estabelecimento de linhas de investigação e especialidades constituíram processos fundamentais nas décadas de 1970 e 1980, no sentido da afirmação das identidades dos espaços acadêmicos específicos de cada área do conhecimento. Paralelamente, e mesmo como uma possibilidade pós-regime autoritário, os espaços de formação e, sobretudo, de partilha, socialização e discussão foram significativamente ampliados, alargando assim a comunicação entre os pesquisadores dedicados à SE.

Nesse sentido, assegurar e expandir o diálogo entre os agentes inseridos no espaço acadêmico específico da SE foi crucial e acabou por determinar a forma como a área foi se organizando e as diretrizes que guiaram os agentes nos primeiros anos que se seguiram à revolução de abril de 1974. A importância dos espaços de diálogo é tamanha que somos levados a observar como, ao longo do tempo, eles foram elementos que, juntamente com os cursos de mestrado e doutoramento e com as unidades de investigação, contribuíram decisivamente para o amadurecimento da área disciplinar da SE neste país. Destaca-se, neste movimento de expansão, o prolongamento da SE para além do contexto universitário, o que desencadeou a associação de pesquisadores em torno deste campo. Sobre isso, faz-se mister destacar que 


\begin{abstract}
A organização de um espaço acadêmico específico em instâncias para além da instituição universitária compõe a realidade portuguesa há mais de um século. Contudo, mais uma vez trata-se de instâncias repelidas pelo período ditatorial. As associações de investigadores que foram constituídas antes mesmo da década de 1930 - e mesmo as que nasceram no período salazarista tiveram sua atuação minimizada até 1974, é o caso das Sociedades Portuguesas de Química (1911) e Matemática (1940). No seguimento da Revolução dos Cravos, a qual foi determinante para o futuro da ciência em Portugal, estas sociedades puderam retomar suas atividades com maior autonomia e o que ocorreu com a abertura democrática foi a constituição de novas associações científicas em diversas áreas do conhecimento, alguns exemplos deste movimento são: as Sociedades Portuguesas de Física (que se separou da Sociedade Portuguesa de Química em 1974), de Filosofia (1977), as Associações Portuguesas de Psicologia (1979), de Linguística (1984) e de Sociologia (1985) (SILVA, 2017, p. 219).
\end{abstract}

A esse cenário de ampliação dos espaços de diálogo no campo científico português de maneira geral, e da SE de modo mais específico, devem ser acrescentados outros espaços decisivos para a aproximação dos pesquisadores e a circulação da sua produção; estamos a falar dos veículos de publicação e divulgação desta produção e dos eventos científicos. As publicações que antecedem a própria autonomização da SE em Portugal - a exemplo de teses, livros e artigos produzidos no país ou no estrangeiro por pesquisadores expatriados que se preocupavam com a temática da educação - são expressões da força que a SE foi ganhando ao longo do tempo, até se tornarem possíveis sua relativa autonomização e sua robustez institucional dentro e fora das universidades, com a criação das associações, das seções e também das revistas especializadas e dos eventos correspondentes. Neste último caso, estamos a falar de congressos, seminários, simpósios, fóruns, mostras, etc., que podem estar vinculados a uma associação científica (mais provavelmente à APS ou à Sociedade Portuguesa de Ciências da Educação, no caso da SE), a algum curso de mestrado ou de doutoramento da área, ou ainda a grupos de investigadores reunidos em torno de uma temática específica dentro do universo de objetos que foram sendo contemplados ao longo do tempo no espaço da SE em Portugal.

Pensando-se em quaisquer áreas do conhecimento, tanto as associações científicas quanto os veículos de divulgação e os eventos constituem, por um lado, espaços importantes de compartilhamento de experiências e resultados parciais e finais de pesquisas, bem como, por outro, verdadeiros fóruns para reflexão e tomadas de posicionamento perante questões epistemológicas, políticas e dos rumos desse campo. Interessa-nos, nesta demonstração da vitalidade da SE portuguesa após a revolução democrática de abril de 1974, tomar a APS e sua Seção Temática de Sociologia da Educação como espaços privilegiados para a consolidação e para constantes exercícios coletivos de autorreflexão da SE neste país. As correntes teóricas, os paradigmas, os objetos de investigação, as tendências temáticas e metodológicas, o papel social da investigação em SE e a relação com a vida pública e política do país são exemplos das questões que marcam os diálogos estabelecidos nestes dois espaços.

A APS foi fundada em 1985, em Lisboa, e contava à época com 30 sócios - número que quase triplicou no ano seguinte, chegando a 86 associados quando das primeiras eleições para sua direção. Trata- 
se de uma associação sem fins lucrativos, reconhecida como Pessoa Coletiva de Utilidade Pública pelo então primeiro-ministro, Aníbal A. Cavaco Silva, no ano de 1991. O professor João de Freitas Ferreira de Almeida, ${ }^{2}$ primeiro diretor da APS (1986-1990), afirmou que a instituição nasceu com ilimitada ambição de melhor conhecer a sociedade portuguesa, de ecoar nas políticas públicas e ainda de encorajar a internacionalização e o trabalho comparativo na produção científica da área. Os objetivos da APS são definidos da seguinte forma:

[...] a) Promover o desenvolvimento da Sociologia em Portugal e a criação de uma comunidade sociológica nacional; b) Encorajar a investigação e dinamizar a comunicação e o debate científicos; c) Incentivar e divulgar a análise sociológica da realidade portuguesa; d) Promover a integração dos sociólogos portugueses na comunidade sociológica internacional; e) Divulgar junto das instituições e da opinião pública a natureza e os contributos da Sociologia; f) Favorecer o relacionamento com outras disciplinas e outras comunidades científicas e grupos sócio-profissionais [sic]; g) Promover a actividade profissional dos sociólogos e garantir um adequado cumprimento do seu código deontológico. (ASSOCIAÇÃO PORTUGUESA DE SOCIOLOGIA, 2008, Artigo $2^{\circ}$ ).

As noções de agrupamento, colaboração e integração dos sociólogos constituem marcas fundamentais nesses objetivos, o que revela o consenso entre os associados acerca da construção de uma associação que se dedica a fortalecer a Sociologia em Portugal, ao passo que se coloca as tarefas de promover a área, sua comunidade, a produção sociológica, o diálogo com outras áreas do conhecimento e ainda a atividade profissional dos sociólogos e das sociólogas. Este último elemento, relacionado à profissão propriamente dita, é levado a cabo com base nas seguintes frentes de atuação: 1) a discussão sobre a natureza ética da classe profissional, pelo que a APS conta com um Conselho de Deontologia próprio e com um código deontológico; 2) o estudo sobre os sociólogos portugueses e suas práticas e condições profissionais, frente em que a associação compila e socializa dados sobre o perfil dos diplomados em Sociologia no país e ainda realiza um inquérito nacional sobre as práticas profissionais dos diplomados na área; e 3) a preocupação com a colocação profissional dos sociólogos em Portugal, iniciativa que conta com a divulgação de ofertas de emprego e bolsas para os associados em sua página na internet, bem como com a definição de saídas profissionais para a formação em Sociologia e ainda com o projeto 'Portfólio profissional de sociólogos', que oferece visibilidade para as atividades dos sociólogos portugueses. ${ }^{3}$

Com 35 anos de atuação, o crescimento da Sociologia portuguesa tem sido demonstrado, dentre outros elementos, pela atuação da APS, instituição que, no contexto português, “[...] congrega o maior número de associados estudantes e profissionais de sociologia" (RODRIGUES, 2009, p. 3). Uma marca de seu alcance encontra-se nas edições do Congresso Português de Sociologia, organizado pela APS, que tem crescimento exponencial a cada edição - o evento se realiza a cada quatro anos - e apresenta uma gama diversificada de temáticas, colóquios, pesquisadores inscritos e trabalhos apresentados. Além disso, os posicionamentos da APS perante as questões hodiernas nacionais e internacionais - que englobam as 
relações dos cenários social, político, econômico, cultural etc. - também acabam por constituir uma marca de sua atuação na sociedade portuguesa.

É no seu estatuto que a APS prevê a criação de seções temáticas de alcance nacional, bem como de núcleos de âmbito regional, como forma de promover a organização de ramos específicos da Sociologia. As propostas de criação desses espaços específicos devem partir dos associados, ser encaminhadas à direção da associação e depois deliberadas em assembleia geral. E, no que tange à dinâmica de funcionamento das seções ou núcleos, cada agrupamento cria seu próprio regulamento, o qual passa pela ratificação da assembleia geral. Atualmente, a APS conta com 21 seções temáticas, nomeadamente: Sociologia da Saúde; Sociologia da Infância; Sociologia dos Direito e Justiça; Sexualidade e Gênero; Ambiente e Sociedade; Arte, Cultura e Comunicação; Famílias e Curso de Vida; Conhecimento, Ciência e Tecnologia; Sociologia da Religião; Sociedade Civil, Economias Alternativas e Voluntariado; Trabalho, Organizações e Profissões; Sociologia do Turismo; Migrações, Etnicidade e Racismo; Diversidades Culturais e Espaços de Intervenção; Sociologia do Desporto; Sociologia do Consumo; Sociologia das Emoções; Segurança, Defesa e Forças Armadas; Classes, Desigualdades e Políticas Públicas; Pobreza, Exclusão Social e Políticas Sociais; Sociologia da Educação. Além disso, registra-se também o Núcleo dos Açores, único grupo regional em funcionamento neste momento.

A multiplicidade de ramos da Sociologia que emergem da observância a essas seções é expressão do papel da APS em Portugal, mas também da pluralidade e diversidade que marcam o trabalho dos sociólogos neste país. A Seção de Sociologia da Educação, sobre a qual nos debruçaremos a partir de agora, deve ser compreendida, portanto, neste cenário de consolidação da Sociologia portuguesa, que permite estes movimentos de integração dos sociólogos em torno da grande área e, concomitantemente, em torno das especificidades de cada ramo que vai se autonomizando no interior da Sociologia. Se a APS pode ser compreendida como uma importante expressão da maturidade e consolidação da Sociologia em Portugal, a Seção de Sociologia da Educação representa, pois, um processo semelhante no tocante à SE.

A Seção de Sociologia da Educação foi a primeira a constituir-se na APS, derivando de um movimento orgânico de diálogo e reflexões que ganharam espaço em dois eventos científicos, o 'Congresso Português de Sociologia', em 2008, e a 'Jornada Contextos Educativos na Sociedade Contemporânea', em 2009 (PALHARES, 2010). Seu objetivo principal consiste em estimular o diálogo e a colaboração entre especialistas e interessados neste campo científico, bem como em promover o desenvolvimento do campo na sociedade portuguesa. A primeira equipe a coordenar a Seção de Sociologia da Educação da APS era composta por Pedro Abrantes, Ana Matias Diogo e José Augusto Palhares, a qual foi sucedida, a partir de 2014, pelos professores Bruno Dionísio, Leonor Lima Torres e Mariana Gaio Alves. A robustez desta seção pode ser aferida pelo quantitativo de sujeitos que a compõem: atualmente são 151 associados, dentre os 
quais estão representados diferentes grupos dedicados à SE em Portugal - geográfica, geracional, teórica e metodologicamente diferentes -, mas que levam estas diferenças como um elemento constitutivo da SE portuguesa e prezam por um espaço de trocas, diálogos, socialização das investigações, análise coletiva dos percursos que se tem percorrido e tomadas de decisão quanto aos direcionamentos futuros. ${ }^{4}$

Esta organização de um grupo próprio no seio da associação em questão demonstra exatamente a capacidade organizacional e integrativa dos pesquisadores em SE no país e, sobretudo, acaba por sublinhar, de modo mais amplo, o papel de espaços de integração de agentes de uma mesma área do conhecimento no campo científico: trata-se de uma tendência que vemos ao redor do mundo e que ratifica o caráter colaborativo do desenvolvimento da ciência e de sua comunidade.

Agenda de pesquisa e marcas teórico-metodológicas: a Seção de Sociologia da Educação da APS em análise

Na primeira newsletter da Seção de Sociologia da Educação da APS, no editorial assinado por José Augusto Palhares (2010, p. 1), lemos a seguinte tarefa assumida pelos pesquisadores da área: “[...] no fundo, caberá à nossa secção indagar persistentemente 'de que falamos quando falamos de educação? "'. Este questionamento guarda em si uma preocupação inicial dos membros desta seção quanto à reflexão constante acerca do próprio trabalho que desenvolvem nas suas investigações e publicações, das orientações e dos trabalhos de seus estudantes e, de modo coletivo, da produção em SE no país. O reconhecimento de uma SE plural, ou seja, que apresenta diferentes respostas para o questionamento acima e cotidianamente tem construído novos olhares epistemológicos e novas matrizes de conhecimento, é a indicação de Palhares para a compreensão do campo da SE no cenário atual.

Esta seção foi objetivada por Dionísio, Torres e Alves (2018) com vistas a correlacionar a história do desenvolvimento da SE portuguesa com as entrevistas realizadas com sociólogos da educação publicizadas nas newsletters da seção em questão, portanto esses autores centraram-se em um dos elementos constitutivo desse material (as entrevistas, a perspectiva de memória da SE e suas perspectivas de futuro), e é precisamente aqui onde nossa análise diferencia-se: centramo-nos, pois, nas newsletters tomadas em sua totalidade, ou seja, todos os itens que a compõem foram escrutinados, bem como os das atas dos encontros promovidos pela Seção de Sociologia da Educação. O alvo de nossa análise, por um lado, está no mapeamento simultâneo de uma produção própria dos membros da seção estudada - visto que as newsletters são necessariamente fruto dos esforços da coordenação, juntamente com os associados, no sentido de explicitar a produção, os debates e perspectivas que movimentam esta seção - e, por outro, em uma produção mais difusa, veiculada nas atas dos encontros, que nos apresenta não somente um produto restrito aos associados mas também um conjunto mais amplo de sujeitos que compõem direta ou 
indiretamente o campo da SE portuguesa (e aqui também entra um diálogo com outros países, em função da participação estrangeira nos eventos).

O que as newsletters revelam, então, sobre a seção aqui estudada e, no seu prolongamento, sobre a SE portuguesa? Responderemos a esta questão com a apresentação de três marcas identificadas nos processos de categorização e análise dos dados, a saber: 1) movimento constante de autorreflexão; b) principais temas abordados; e c) produtores e suas instituições.

A primeira marca é aquela que revela um dos principais motivos para a produção das newsletters da seção, visto que este material busca divulgar as atividades, as produções, os eventos, as lutas e os debates da SE em Portugal e no mundo - e aqui entram as análises realizadas sobre as tendências em SE de âmbito internacional presentes nas newsletters -, bem como constituir-se como um espaço de autoanálise dos caminhos percorridos pela seção e pela área de maneira mais ampla. $\mathrm{O}$ ato de interrogar o passado, o presente e o futuro marca esses exercícios autoanalíticos. Nesse sentido, o objeto de análise do estudo de Dionísio, Torres e Alves (2018), qual seja, as entrevistas com Sérgio Grácio Bruno Dionísio, Telmo Caria, Sofia Marques da Silva, Carlos Alberto Gomes, Maria Manuel Vieira, Almerindo Janela Afonso e Teresa Seabra, é um ótimo exemplo da tarefa que a seção se colocou ao refletir sobre sua própria história e suas perspectivas de futuro. Isso porque essas entrevistas tratam de resgatar as memórias formativas e profissionais dos professores e pesquisadores supracitados, bem como de ouvir suas visões quanto à atualidade de seus temas e objetos de investigação, e as suas prospecções para o futuro da própria SE em Portugal.

Ao categorizarmos e analisarmos esta marca da autorreflexão, foi-nos possível construir três frentes que emergem das newsletters, as quais podem ser visualizadas na Tabela 1, abaixo:

Tabela 1 - Movimento de autorreflexão presente nas newsletters da Seção de Sociologia da Educação da Associação Portuguesa de Sociologia

\begin{tabular}{|c|c|c|}
\hline \multicolumn{3}{|l|}{ Frente I: Sociologia da Educação no cenário nacional } \\
\hline Detalhamento & $\mathbf{N}^{\mathbf{0}}$ & $\%$ \\
\hline História da Sociologia da Educação portuguesa (origens, processo de consolidação) & 9 & $11,00 \%$ \\
\hline Entrevistas com sociólogos da educação & 8 & $9,10 \%$ \\
\hline Eventos nacionais & 5 & $6,00 \%$ \\
\hline Formação de professores e profissionais em Sociologia da Educação & 4 & $4,50 \%$ \\
\hline Diálogo entre Sociologia e Ciências da Educação & 3 & $3,90 \%$ \\
\hline Balanços nacionais sobre a Sociologia da Educação portuguesa & 3 & $3,90 \%$ \\
\hline Objetos de investigação proeminentes em Sociologia da Educação & 2 & $2,30 \%$ \\
\hline Papel da Sociologia da Educação na sociedade portuguesa & 2 & $2,30 \%$ \\
\hline $\begin{array}{l}\text { Outros (Ensino de Sociologia da Educação; Redes de pesquisa; Posição da Sociologia da } \\
\text { Educação portuguesa na Europa; Referenciais teórico-metodológicos; Oferta de bolsas no } \\
\text { país; Autonomia da Sociologia da Educação) }\end{array}$ & 6 & $7,00 \%$ \\
\hline
\end{tabular}




\begin{tabular}{|c|c|c|}
\hline Total da frente & 42 & $50,00 \%$ \\
\hline \multicolumn{3}{|l|}{ Frente II: Sociologia da Educação no cenário internacional } \\
\hline Detalhamento & $\mathbf{N}^{\mathbf{o}}$ & $\%$ \\
\hline $\begin{array}{l}\text { Países/regiões e a Sociologia da Educação na cena internacional (Brasil; França; } \\
\text { Inglaterra; Estados Unidos; Cabo Verde; Espanha; Europa e Europa do Sul) }\end{array}$ & 16 & $19,50 \%$ \\
\hline Eventos internacionais & 4 & $4,50 \%$ \\
\hline Balanços internacionais sobre a Sociologia da Educação & 2 & $2,30 \%$ \\
\hline Redes internacionais de pesquisa & 2 & $2,30 \%$ \\
\hline Papel da Sociologia da Educação na sociedade & 1 & $1,40 \%$ \\
\hline Total da frente & 25 & $30,00 \%$ \\
\hline \multicolumn{3}{|c|}{ Frente III: A Seção de Sociologia da Educação da Associação Portuguesa de Sociologia } \\
\hline Detalhamento & $\mathbf{N}^{\circ}$ & $\%$ \\
\hline Eventos científicos promovidos pela seção & 3 & $3,90 \%$ \\
\hline História da seção & 2 & $2,30 \%$ \\
\hline Futuro da Sociologia da Educação e da seção & 2 & $2,30 \%$ \\
\hline A seção e o debate público & 2 & $2,30 \%$ \\
\hline Newsletter como espaço de reflexão & 2 & $2,30 \%$ \\
\hline Diferentes gerações de pesquisadores na seção e cooperação & 2 & $2,30 \%$ \\
\hline Mudança na coordenação da seção & 2 & $2,30 \%$ \\
\hline Objetos de pesquisa/reflexão proeminentes no âmbito da seção & 2 & $2,30 \%$ \\
\hline Total da frente & 17 & $20,00 \%$ \\
\hline
\end{tabular}

Fonte: Elaboração própria.

Alguns elementos que se fazem presentes nas três frentes acima representadas merecem destaque; veem-se claramente reflexões construídas em torno de questões como: os balanços nacionais e internacionais, bem como os principais objetos de pesquisa em SE; o papel social da SE nos cenários nacional e internacional e o papel da seção no debate público português; a divulgação e análise dos eventos científicos da área. Os tempos e espaços da SE portuguesa vão, pois, ganhando destaque nas newsletters da seção neste movimento de autorreflexão, o que se deve às análises apresentadas sobre: os eventos realizados, os debates nacionais e internacionais, as investigações em andamento e concluídas, as novidades editoriais, as publicações em periódicos, entre outros. Emerge deste movimento a compreensão, por parte dos produtores das newsletters, de que a SE portuguesa é bastante difusa em diferentes agrupamentos de pesquisadores e suas iniciativas, nas faculdades e nos institutos de Sociologia e de Ciências da Educação, em unidades de investigação, em grupos de pesquisa, periódicos, eventos científicos e ainda nas parcerias e redes de pesquisa com pesquisadores de outros países - todos estes espaços diversificados foram, pois, contemplados, divulgados ou analisados nas newsletters da Seção de SE da APS. 
O movimento de reflexividade vislumbrado nesta produção da seção que estamos a analisar ganha um sentido muito próximo daquilo à que Bourdieu (2004) chamava atenção em seus escritos sobre o campo científico, a saber, a necessidade de a instituição científica produzir uma reflexão coletiva sobre si própria. Para o autor, mais do que as indicações de comitês e comissões externas, que figuram nas instâncias de avaliação da ciência, as formas de autorreflexão precisam ser construídas coletivamente pelos agentes que criam o campo científico, o qual só existe, de alguma maneira, pelos agentes e pelas suas relações objetivas.

A segunda marca que nosso estudo identificou a partir da análise das newsletters diz respeito aos principais temas que figuraram neste material ao longo dos anos. O corpus de 16 newsletters, publicadas entre 2010 e 2016, foi escrutinado de modo a possibilitar o mapeamento das temáticas que foram abordadas pela Seção de Sociologia da Educação neste período. A pluralidade de objetos de estudo e investigação da SE vem se apresentando como uma regra nos diferentes contextos nacionais em que este campo se desenvolve e se consolida, não sendo, portanto, uma característica específica da SE portuguesa (FURLONG; LAWN, 2009, 2011; OLIVEIRA; SILVA, 2016), e foi exatamente esta característica da diversificação temática que emergiu da análise que aqui empreendemos.

Nesse sentido, uma síntese do modo como as temáticas são recorrentemente tratadas na seção aqui estudada pode ser observada no Gráfico 1, abaixo, cujo intuito reside na observância à pluralidade que se apresenta nos debates enfrentados pela Seção de Sociologia da Educação da APS e, necessariamente, também se coloca para a SE portuguesa de modo mais geral.

Gráfico 1 - Temáticas presentes nas newsletters da Seção de Sociologia da Educação da APS

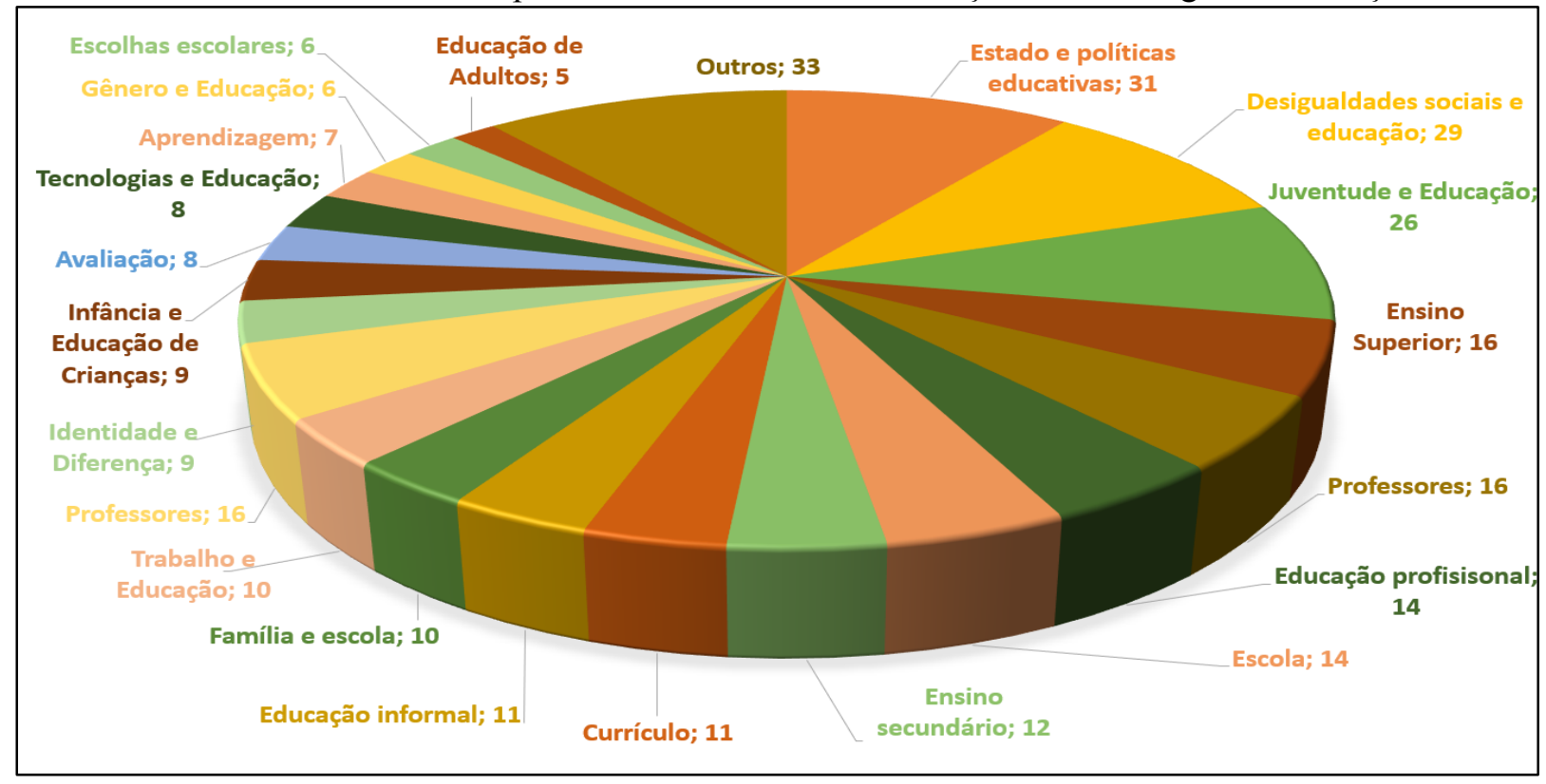

Fonte: Elaboração própria. 
A gama de temáticas que marcam as newsletters da Seção de Sociologia da Educação da APS acaba por levantar um debate sobre as agendas de pesquisa e as preocupações que têm ganhado legitimidade no interior do campo da SE em Portugal. Alguns autores apontam que a Sociologia da Educação portuguesa foi vista, durante muito tempo, como uma "Sociologia da escola", dada a ênfase que historicamente tem se colocado nesta instituição educacional (ALVES, 2017; DIONÍSIO; TORRES; ALVES, 2018). Contudo, tal como aponta Alves (2017, p. 6),

\begin{abstract}
A sociologia da educação em Portugal, como de resto noutros países, tem sido em grande parte uma sociologia da escola, ou seja, uma sociologia dos processos e sistemas educativos formais, tanto no quadro das ciências da educação como enquanto subespecialização da sociologia. Porém, novos desafios têm vindo a ser enfrentados nesta área científica, quer no plano das problemáticas e objetos de reflexão, quer no que respeita à renovação de abordagens teórico-conceptuais e de modelos de análise. Tal não significa que a escola deixe de ser um espaço e tempo privilegiado de educação ou um objeto menos importante da análise sociológica, mas sublinha-se, em vez disso, a necessidade de equacionar os sistemas formais de educação em estreita articulação com espaços e tempos nãoescolares [sic passim] de educação.
\end{abstract}

A mirada para os debates da seção investigada é reveladora da multiplicidade de temas de que os sociólogos da educação têm se ocupado nos últimos anos. É verdade que a escola aparece com bastante força neste cenário, e certamente ainda deve ser apontada como um dos temas e objetos principais da SE portuguesa, contudo os dados trazidos pelo Gráfico 1 não deixam dúvidas quanto à complexidade e diversificação de aspectos da realidade educacional que têm sido acrescidos às reflexões sociológicas sobre a educação. Se levarmos em consideração o papel da seção aqui estudada no cenário mais amplo da SE nacional, o conjunto de temas que ganhou espaço nas suas newsletters possui uma relação bastante próxima com aquilo que, de fato, foi legitimado como agenda de pesquisa da SE portuguesa - o que pode ser confirmado não somente pelas posições ocupadas pelos coordenadores e associados da seção no campo científico mais amplo da SE mas também pelo próprio papel dessas newsletters como um canal de discussão e divulgação daquilo que foi realizado e daquilo que foi ganhando notoriedade para os sociólogos da educação portugueses.

Em função dessa compreensão, a perspectiva bourdieusiana nos auxilia a compreender que os principais temas representados no Gráfico 1 - tais como Estado e políticas educativas; Desigualdades sociais; Juventude; Ensino Superior; Professores; Educação profissional; Escola; etc. - são fruto de uma luta simbólica por poder no interior do campo da Sociologia da Educação em Portugal, e esta luta tem por objetivo a conquista de uma autoridade científica no direcionamento dos temas e objetos que serão considerados dignos. O mesmo vale, em uma escala hierárquica, que também é valorativa e simbólica, para aqueles temas e objetos considerados indignos (BOURDIEU, 2011, 2013), que, no caso do corpus analisado, ou figuram na categoria 'Outros', ${ }^{5}$ ou nem sequer foram contemplados nas newsletters. 
A última marca das newsletters identificada em nossas análises diz respeito aos produtores e suas instituições. Afinal, quem são os agentes que estavam envolvidos na feitura desse material e continuaram com a escrita de suas colunas? O engajamento dos professores e pesquisadores neste empreendimento de construção de newsletters pode ser visualizado pela frequência com a qual eles colaboraram como autores dos segmentos do material. Vejamos, então, por ordem de contribuição: Pedro Abrantes (assina 12 colunas); José Augusto Palhares (11); Ana Matia Diogo (8); Leonor Torres (5); Mariana Gaio Alves (3); Fátima Antunes (2); Bruno Dionísio (2); Sofia Gaspar (1); Virgínio Sá (1); Arlinda Cabral (1); Paula Guimarães (1); Irina Bettencourt Pereira (1); Maria Manuela Mariani (1); Sofia Castro Pereira (1); Teresa Costa (1); Miguel Martins (1); Teresa Seabra (1); Suzana da Cruz Martins (1); Manuel Silva (1); Ana Cristina Palos (1); Almerindo Janela Afonso (1) ${ }^{6}$. Esses nomes acabam por demonstrar que as newsletters constituíram um esforço das coordenações da seção em parceria com um grupo de associados.

É possível ainda vislumbrar, a partir desse elenco, as instituições que, de certo modo, estavam vinculadas indiretamente a este trabalho colaborativo de produção de um material próprio da Sociologia da Educação portuguesa, no sentido de reunir informações relevantes sobre o que estava sendo desenvolvido no país e no cenário internacional, bem como de difundir reflexões diversas. O Instituto Universitário de Lisboa (ISCTE-IUL) aparece com maior representação (com 7 sujeitos vinculados), seguido pela Universidade do Minho (6), a Universidade Nova de Lisboa (2), a Universidade dos Açores (2), a Universidade de Lisboa (1), o Politécnico de Portalegre (1) e o Centro de Formação do Seixal (1). Naturalmente, essa distribuição geográfica não pode ser tomada como totalidade para pensarmos a SE no país, mas ela nos oferece um breve quadro acerca da atuação mais incisiva na seção em questão, assim como um vislumbre das relações de força entre as diferentes instituições e regiões do país quando se toma o desenvolvimento da SE em Portugal como objeto de análise no contexto das lutas pelo monopólio da definição legítima da prática científica neste campo (BOURDIEU, 2004).

Em complementaridade a esta análise que realizamos das newsletters da Seção de Sociologia da Educação da APS, debruçamo-nos também sobre os três encontros que foram organizados por esta instância. As reverberações teórico-metodológicas constituíram o fio condutor da categorização e análise do material oriundo das atas dos encontros promovidos pela seção em questão. Nesse sentido, antes de adentrarmos propriamente na discussão de tais reverberações, faz-se necessário trazer aqui algumas informações relevantes sobre os eventos em questão: a) estamos a falar dos I, II e III Encontros de Sociologia da Educação, realizados respectivamente em 2009 (Lisboa), 2011 (Porto) e 2013 (Braga); b) os temas desses eventos foram, na devida ordem cronológica, 'Contextos educativos na sociedade contemporânea', 'Educação, territórios e (des)igualdades' e 'O não-formal e o informal em Educação: centralidades e periferias'; c) o encontro realizado no ano de 2013 ocorreu de forma integrada com o 'I 
Colóquio Internacional de Ciências Sociais da Educação'. Compreendemos, pois, a construção e organização desses encontros como mais uma das manifestações da envergadura e maturidade da Seção de Sociologia da Educação.

A análise realizada deteve-se às atas dos eventos, que se encontram disponíveis na aba da seção na página eletrônica da APS, e o material analisado é composto dos trabalhos que foram publicados nessas atas. Sabendo do diálogo ampliado que esses congressos possibilitaram, inclusive atraindo pesquisadores estrangeiros, é preciso estabelecer aqui que a leitura desses trabalhos deve ligar-se exatamente à capacidade dialógica da SE portuguesa e da seção correspondente, uma vez que os eventos em questão são marcados por intercâmbios entre agentes que compõem diferentes campos.

As principais temáticas contempladas nos trabalhos foram organizadas e categorizadas da seguinte forma:

Gráfico 2 - Principais temáticas presentes nos trabalhos publicados nas atas dos encontros da Seção de Sociologia da Educação da Associação Portuguesa de Sociologia

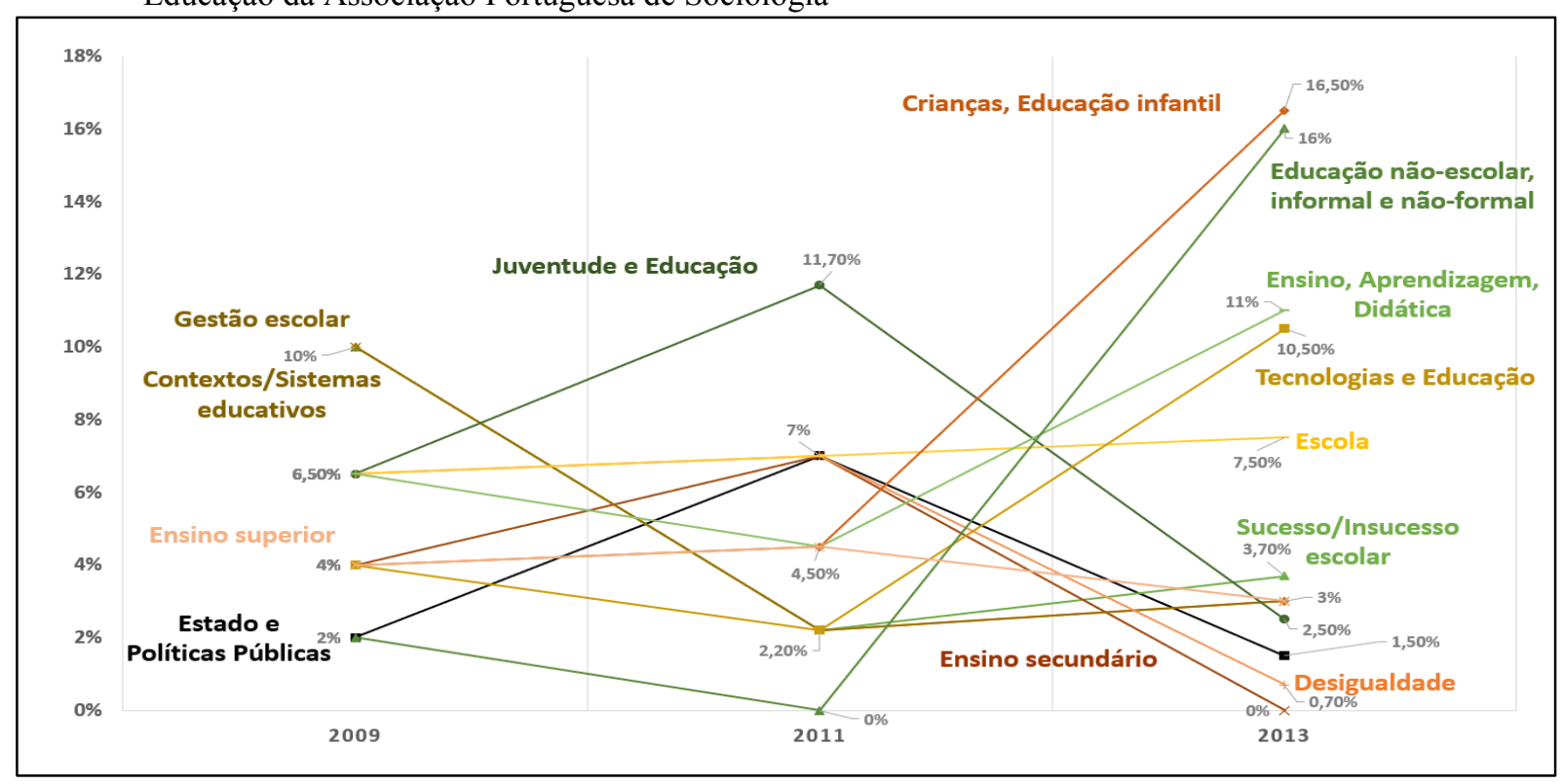

Fonte: Elaboração própria.

A maior parte das temáticas que figuram no Gráfico 2 perpetuam-se nos três encontros, o que é sintomático daquilo que foi se consolidando no cenário recente em termos de agenda de pesquisa da SE. Conforme essa representação gráfica, somente os temas ‘Ensino secundário’ (nenhum trabalho referente no ano de 2013) e 'Educação não-escolar, informal e não-formal' (nenhum trabalho referente no ano de 2011) estiveram ausentes dos trabalhos apresentados nesses eventos. Quanto a esse dado, há ainda que se adicionar as seguintes temáticas - que, apesar de terem aparecido nas atas analisadas, não possuíam força percentual suficiente para estarem representadas no gráfico em questão, ou seja, manifestaram-se de forma tímida no parâmetro numérico: Trabalho e Educação (contemplada em 2009 e 2013); Sujeitos escolares 
(2009 e 2011); Educação de tempo integral (2009 e 2013); Comunicação e Educação (2009 e 2013); Educação profissional (2009 e 2011); Gênero e sexualidade (2009 e 2011); Violência (2009 e 2011); Inclusão (2011 e 2013); Currículo (2011 e 2013); Avaliação (2011 e 2013); Escolhas escolares (2009); Educação de adultos (2011); Relações étnico-raciais (2013); Família e escola (2013); Identidade e Diferença (2013); Educação indígena (2013).

Chama atenção o fato de alguns desses temas coincidirem com aqueles dos quais a seção ocupouse na feitura de suas newsletters, como: juventude, escola, políticas públicas, educação informal, infância, entre outros, o que revela uma relação de prolongamento entre o campo mais amplo da SE portuguesa e a seção em questão, bem como uma espécie de auscultação das questões sociais e educacionais que se apresentam em cada período.

O conjunto de temáticas debatidas nos congressos da Seção de Sociologia da Educação, assim como este movimento de continuidade e descontinuidade, é uma das maiores expressões do alcance deste campo e da diversificação de problemáticas e objetos de investigação que têm marcado os trabalhos dos pesquisadores da área. Esta questão demonstra ainda a identidade plural que a SE vem construindo, o que não é exclusividade da experiência portuguesa de desenvolvimento e consolidação desse campo (CUNHA, 1992; AFONSO, 2001; LAUDER; BROWN; HALSEY, 2009; OLIVEIRA; SILVA, 2016), e, portanto, vai ao encontro dos questionamentos acerca da necessidade de falarmos em Sociologias da Educação, sim, no plural, de modo a abarcar a diversidade que se apresenta em seu interior. O incremento do número de pesquisadores em SE, os interesses renovados desses agentes, bem como a própria dinâmica social, que impõe cotidianamente novos desafios para pensarmos a educação, podem ser apontados como elementos explicativos para esta diversificação das temáticas.

Neste ínterim, o pluralismo expressa-se também nos referenciais teóricos e metodológicos que emergem dos trabalhos publicados nas atas dos encontros aqui analisados. Ao mapearmos a recorrência dos quadros teórico-metodológicos neste material, algumas questões destacaram-se ainda no processo de levantamento e categorização, a saber: a) os trabalhos não fazem uso estrito de referências puramente da Sociologia ou da SE: é notório um amplo diálogo com outras disciplinas, como História, Filosofia, Ciência Política, Antropologia, Economia, Comunicação e Letras e Literatura; b) nas três edições dos eventos há uma marcante presença de pesquisadores estrangeiros, o que assevera a capacidade aglutinadora da Seção de Sociologia da Educação da APS e do próprio campo da SE - neste aspecto os pesquisadores brasileiros são aqueles que figuram em maior número, fato que pode ser explicado, e aqui transbordamos a SE e falamos de praticamente todas as áreas do conhecimento, pelo histórico estabelecimento de laços acadêmicos e de redes de pesquisa entre Portugal e Brasil; e c) não foi possível mapear os sujeitos e suas instituições - como realizamos com as newsletters -, pois as informações disponíveis nas atas dos encontros 
variam de um ano para o outro, portanto o encontro de 2013 não traz a explicitação da filiação institucional dos autores e coautores dos trabalhos apresentados.

No que tange aos principais referenciais teórico-metodológicos, partimos de uma análise acerca dos principais autores utilizados nos trabalhos, com vistas a compreender quais as marcas e reverberações que têm assinalado a SE do ponto de vista dos diálogos epistêmicos e conceituais. Rapidamente, durante o trabalho de levantamento, evidenciou-se a extensão do diálogo promovido nos trabalhos analisados; visto que a literatura utilizada contempla diferentes países, escolas e tradições teóricas, destacamos a presença de autores oriundos de países como Brasil, Inglaterra, Estados Unidos, França, México, Espanha, entre muitos outros - antes de explorar a expressividade dos referenciais estrangeiros nesses trabalhos, faz-se mister destacar que os autores portugueses ocupam posição privilegiada nas referências desses trabalhos, com destaque para nomes como António Nóvoa, ${ }^{7}$ Rui Grácio, Maria Teresa Estrela, Stephen Stoer, Ana Benavente, Pedro Abrantes, Rui Canário, Almerindo Janela Afonso, entre outros.

No âmbito das influências estrangeiras, percebe-se que, em alguns casos, a exemplo do Brasil, dos Estados Unidos e da Inglaterra, a literatura referenciada dispersa-se em uma multiplicidade de nomes que, necessariamente, estão diretamente ligados ao tema e/ou objeto de estudo dos trabalhos analisados. Exatamente por este movimento de dispersão, evidenciam-se, afinal, a influência e o diálogo mais geral da SE brasileira, norte-americana e inglesa com o campo científico português. Contudo, há um caso que chama atenção e merece aqui a explicitação de seus números - em função de seu alcance percentual, coletivo e individual: estamos a falar da SE francesa. Do conjunto das referências estrangeiras, as menções à literatura francesa chegam a aproximadamente $30 \%$, dentre as quais demonstram notoriedade: Pierre Bourdieu (citado 163 vezes nas atas dos três encontros); Bernard Lahire (citado por 97 vezes); François Dubet (citado 75 vezes); e Bernard Charlot (46 citações). Este quadro nos fala, concomitantemente, da posição que a SE francesa ocupa no cenário global do campo científico, da histórica ponte que os sociólogos portugueses têm construído e legitimado com a França - o que se expressa tanto pela utilização desta literatura na produção portuguesa quanto pelo número de professores e pesquisadores portugueses que realizaram alguma etapa da sua formação na França, e ainda pelas parcerias e redes de pesquisa firmadas nas últimas décadas entre Portugal e França e outros países francófonos.

$\mathrm{O}$ design metodológico constituiu uma frente de mapeamento bastante complexa, uma vez que a apresentação dos caminhos percorridos em cada estudo e pesquisa, nos trabalhos publicados nas atas dos encontros, obedece a lógicas bastante distintas, o que impede uma categorização convencional das informações. Para lidar com isso, o próprio trabalho com o corpus do estudo nos revelou que aquilo que ligava os trabalhos nos três eventos, no plano metodológico, era a operacionalização das pesquisas. Foi possível observar a seguinte configuração: ${ }^{8}$ há um número considerável de trabalhos que fez uso de uma 
combinação de abordagens, técnicas e instrumentos para a realização da investigação desenvolvida (42\%), destacando-se aqui a associação de pesquisa documental e pesquisa de campo. A abordagem qualitativa é aquela que predomina nos trabalhos, com um percentual de 75\%, aproximadamente, porque é bastante comum a falta de indicação de que abordagem fora adotada nos trabalhos. A pesquisa de campo também aparece com bastante força nos trabalhos (cerca de 51\%), e aqui figuram com destaque a escola, a universidade e, especialmente no ano de 2013, os espaços não-escolares. Os trabalhos assentados em pesquisa documental e/ou em análise de dados secundários (cerca de 46\%) giravam, especialmente, em torno de políticas e legislação educacional e de informações de órgãos e agências nacionais e internacionais ligados à educação; um pequeno número dos trabalhos (em torno de 2,5\%) desenvolveu estudos de cunho teórico, voltados exclusivamente para a discussão do pensamento de determinado(a) autor(a) sobre a Educação, com destaque para Émile Durkheim e Michel Foucault.

Tomar a Seção de Sociologia da Educação da APS como objeto de análise nos levou a um movimento duplo: objetivamos a produção do próprio núcleo da seção, por meio das suas newsletters, bem como as atas dos congressos que este mesmo núcleo organizou, e aqui trouxemos para a análise a produção mais abrangente dos agentes que dialogam direta e indiretamente com a SE portuguesa. O exercício analítico acabou por evidenciar não somente o papel crucial da seção investigada nesse momento de maturidade do campo mas também o caráter transnacional que se coloca nos processos de legitimação de uma agenda de pesquisa e dos temas, objetos e discussões que vão ganhando espaço nos fóruns ligados à SE em Portugal. As principais marcas da SE na atualidade, expressas nos espaços proporcionados pela seção em questão, foram aqui apresentadas sob as formas das temáticas abordadas, dos agentes engajados no jogo científico e de suas instituições, do quadro teórico-metodológico que tem servido de base para os trabalhos nesta área - estas marcas são, finalmente, reveladoras de um campo científico maduro, consolidado, que possui tempos e espaços diversificados e dialoga com referenciais teóricos e metodológicos de domínios distintos, nacionais e internacionais, promovendo uma verdadeira simbiose na tarefa de pensar sociologicamente as questões educacionais da sociedade portuguesa e também sua relação, em perspectivas comparadas, com outros contextos nacionais.

\section{Considerações finais}

Os espaços e tempos da SE portuguesa são múltiplos e têm sido paulatinamente diversificados, o que se relaciona diretamente com o seu desenvolvimento e consolidação enquanto espaço acadêmico específico relativamente autônomo no interior do campo científico português. A história da SE neste país, sua autonomização recente, impulsionada pelo fim do período autoritário na década de 1970, sua entrada e organização no interior das universidades, nos entrecruzamentos das áreas de Sociologia e das Ciências da 
Educação, constituem elementos dos processos de conquista de maturidade que foram cruciais para os passos posteriores, relacionados à construção de espaços para além das instituições de ensino superior. Estamos a falar da capacidade dos agentes que fazem parte do campo da SE em Portugal, que, nas últimas décadas, além de demarcarem seus territórios em suas faculdades e institutos e formarem seus orientandos, também criaram conjuntamente unidades de investigação, grupos de pesquisa, periódicos especializados, eventos científicos e grupos de trabalho ou seções no interior de associações científicas.

Em que pese a multiplicação de textos que se dedicam a analisar o percurso de construção, desenvolvimento e consolidação da SE em Portugal nas últimas décadas, buscamos oferecer uma mirada voltada para um espaço específico de integração, diálogo e socialização entre os agentes que se dedicam à SE no país. A APS, com seus 35 anos de atuação no campo científico português, foi tomada aqui como um importante espaço de consolidação da Sociologia. Com as possibilidades de agrupamento que esta associação permite em torno dos ramos específicos da Sociologia, a Seção de Sociologia da Educação foi tomada como objeto de análise, com vistas a contribuir com os exercícios de autorreflexão que vêm povoando a literatura especializada deste campo desde os anos de 1980.

A SE portuguesa, por meio de sua seção na APS, tem apresentado, nas suas publicações, uma dupla tarefa: ao mesmo tempo em que se dedicam a avançar no debate e na construção de conhecimentos sociológicos sobre educação, os agentes que compõem este campo têm igualmente buscado refletir acerca do próprio percurso da SE. Este é um movimento bastante interessante, pois nos possibilita compreender que a SE tem conseguido direcionar seu histórico arcabouço epistêmico, teórico e metodológico não somente para os objetos de investigação dos quais se ocupa, já que paralelamente o tem direcionado, com a mesma atitude crítica, para si mesma. A SE, reclamada por Pierre Bourdieu desde a década de 1980, tem, pois, estado presente de forma acentuada na trajetória da SE em Portugal.

Desses movimentos de autorreflexão emerge uma maior clareza sobre os caminhos que os agentes deste campo têm percorrido ao longo do tempo. A reflexividade praticada pelos agentes da SE portuguesa encontra-se expressa, entre outras produções, nos dois tipos de materiais sobre os quais nos debruçamos, que compõem nosso corpus de análise: as newsletters e as atas dos encontros da seção estudada. Os dados construídos a partir desse aparato mostraram-se reveladores do pluralismo que marca a SE portuguesa, o qual se expressa nas temáticas, nos objetos, nos agentes e suas instituições, nas influências e nos referenciais teórico-metodológicos que têm figurado nos debates promovidos pela seção correspondente na APS.

Notas

${ }^{1}$ Cf.: https://aps.pt/pt/inicio/. 
${ }^{2}$ A fala do professor encontra-se registrada na página eletrônica da AP, e pode ser consultada na aba sobre o histórico da associação: https://aps.pt/pt/historia-da-aps/.

${ }^{3}$ Todos os documentos e dados que apontamos neste parágrafo podem ser consultados na página eletrônica da APS.

${ }^{4}$ Estas informações foram retiradas do seguinte sítio eletrônico: $\underline{\mathrm{https}}$ ://aps.pt/pt/st educacao/.

${ }^{5}$ Esta categoria condensa aqueles temas que apareceram raras vezes nos conteúdos das newsletters, dentre os quais destacamos: Movimentos sociais e Educação; Sucesso escolar; Biografia, trajetórias; Imigração e Educação; Violência na escola; Gestão escolar; etc.

${ }^{6}$ Uma análise mais acurada sobre os agentes da SE portuguesa e suas relações, suas posições no campo em questão e os capitais de que dispõem ultrapassa a proposta deste artigo, contudo pode ser sinalizada como tarefa futura no exercício de reflexividade deste campo científico.

${ }^{7}$ Este autor português foi citado 80 vezes no conjunto das atas dos três encontros analisados.

${ }^{8}$ As porcentagens aqui podem ultrapassar os $100 \%$, porque um mesmo trabalho pode encaixar-se em mais de uma categoria, bem como pelo uso de categorias não excludentes.

\section{Referências}

ABRANTES, Pedro. Sociologia e ciências da educação: A distância entre nós. Sociologia, Problemas e Práticas, Lisboa, n. 45, p. 117-130, 2004. Disponível em: https://sociologiapp.iscte-iul.pt/pdfs/45/490.pdf. Acesso em: 15 dez. 2021.

ABRANTES, Pedro (org.). Tendências e controvérsias em Sociologia da Educação. Lisboa: Mundos Sociais, 2010.

AFONSO, Almerindo Janela. A sociologia da educação em Portugal: elementos para a configuração do "estado da arte". In: TEODORO, António; TORRES, Carlos Alberto (org.). Educação crítica e utopia: perspectivas para o século XXI. Porto: Afrontamento, 2005. p. 129-158.

AFONSO, Almerindo Janela. Tempos e itinerários portugueses de la Sociología de la Educación: (dis)continuidades en la construcción de un campo. Revista de Educación, Barcelona, n. 324, p. 9-22, 2001. Disponível em: https://bit.ly/3IICylk. Acesso em: 20 nov. 2021.

ALVES, Mariana Gaio. A sociologia da educação em Portugal na viragem do século: uma parte constitutiva das ciências de educação e uma subespecialização da sociologia. Jornal de Sociologia da Educação, Lisboa, n. 0, p. 1-7, maio 2017. Disponível em: https://bit.ly/3DOfkXm. Acesso em: 20 nov. 2021.

ASSOCIAÇÃO PORTUGUESA DE SOCIOLOGIA. Estatuto. Lisboa: APS, 2008. Disponível em: https://aps.pt/pt/estatutos/. Acesso em: 20 nov. 2021.

BOURDIEU, Pierre. Questões de Sociologia. Lisboa: Edições Fim de Século, 2003.

BOURDIEU, Pierre. Os usos sociais da ciência: por uma sociologia clínica do campo científico. Tradução: Barbara Catani. São Paulo: Editora da Unesp, 2004.

BOURDIEU, Pierre. Para uma Sociologia da Ciência. Lisboa: Edições 70, 2008.

BOURDIEU, Pierre. Homo Academicus. Florianópolis: UFSC, 2011.

BOURDIEU, Pierre. Método científico e a hierarquia social dos objetos. In: NOGUEIRA, Maria Alice; CATANI, Afrânio Mendes (org.). Escritos de Educação. 4. ed. Petrópolis, RJ: Vozes, 2013. p. 35-42.

CARIA, Telmo. Debater a Sociologia da Educação em Portugal. Fórum Sociológico, Lisboa, n. 6, p. 33-49, 1995.

CRESWELL, John. Educational research: planning, conducting and evaluating quantitative and qualitative research. 4th. ed. Boston: Pearson Education, 2012.

CUNHA, Luiz Antônio. Reflexões sobre as condições sociais de produção da sociologia da educação: primeiras aproximações. Tempo Social: Rev. Sociol., São Paulo, v. 4, v. 1-2, p. 169- 182, 1992.

DIONÍSIO, Bruno; TORRES, Leonor Lima; ALVES, Mariana Gaio. A sociologia da educação em Portugal: Perspetivas de futuro. Fórum Sociológico, Lisboa, n. 32, série II, p. 59-69, 2018. Disponível em: https://journals.openedition.org/sociologico/2098. Acesso em: 15 dez. 2021. 
EGREJA, Catarina. O ensino da sociologia em cursos superiores de outras áreas de formação: a perspectiva de docentes e diretores. Sociologia, Problemas e Práticas, Lisboa, n. 82, p. 125-143, 2016. Disponível em: https://bit.ly/3IF4ve5. Acesso em: 20 nov. 2021.

FURLONG, John; LAWN, Martin. The disciplines of education in the UK: between the ghost and the shadow. Oxford Review of Education, Oxford, v. 35, n. 5, p. 541-552, 2009. Disponível em: https://bit.ly/3pNQGBb. Acesso em: 20 nov. 2021.

FURLONG, John; LAWN, Martin. (ed.). Disciplines of education: their role in the future of education research. Abingdon, Oxon: Routledge, 2011.

HEY, Ana Paula. Esboço de uma sociologia do campo acadêmico: a educação superior no Brasil. São Carlos: EDUFSCar, 2008.

LAUDER, Hugh; BROWN, Philip; HALSEY, A. H. Sociology of education: a critical history and prospects for the future. Oxford Review of Education, Oxford, v. 35, n. 5, p. 569-585, 2009. Disponível em: https://bit.ly/3Gv0OWs. Acesso em: 20 nov. 2021.

MACHADO, Fernando Luís. Meio século de investigação sociológica em Portugal - uma interpretação empiricamente ilustrada. Sociologia, Porto, v. 19, p. 283-343, 2009. Disponível em: https://bit.ly/3GAc6bS. Acesso em: 20 nov. 2021.

OLIVEIRA, Amurabi; SILVA, Camila Ferreira da. A sociologia, os sociólogos e a educação no Brasil. Revista Brasileira de Ciências Sociais, São Paulo, v. 31, n. 91, p. 1-15, jun. 2016. Disponível em: https://bit.ly/308V5WA. Acesso em: 20 nov. 2021.

PALHARES, José Augusto. Editorial: A newsletter, a secção e a sociologia da educação. Associação Portuguesa de Sociologia, Secção de Sociologia da Educação, Lisboa, [S. l.], mar. 2010. Disponível em: https://bit.ly/3IC2waa. Acesso em: 20 nov. 2021.

RODRIGUES, Elisabete. O lugar do género, dos homens e das mulheres na sociologia portuguesa: uma análise a partir da Associação Portuguesa de Sociologia e seus congressos. In: CIES e-Working Paper, 64., 2009, Lisboa. Anais... Lisboa: ISCTE, 2009. Disponível em: http://www.cies.iscte.pt/destaques/documents/CIESWP64_Rodrigues.pdf. Acesso em: 15 dez. 2021.

SERPA, Sandro. A reflection on Sociology of Education. International Journal of Social Science Studies, [S. l.], v. 6, n. 3, p. 33-39, 2018. Disponível em: https://bit.ly/3yjJTDa. Acesso em: 20 nov. 2021.

SILVA, Camila Ferreira da. (Ciências da) Educação no Brasil e em Portugal: autonomização dos espaços acadêmicos específicos. 2017. 333 f. Tese (Doutorado em Ciências da Educação) - Faculdade de Ciências e Tecnologia, Universidade Nova de Lisboa, Lisboa, 2017.

SILVA, Camila Ferreira da; ALVES, Mariana Gaio. O lugar da sociologia da educação nas ciências da educação: o caso dos programas de mestrado e doutoramento portugueses. Política \& Sociedade, Florianópolis, v. 14, n. 31, p. 17-38, set./dez. 2015. Disponível em: https://bit.ly/3GEGodo. Acesso em: 20 nov. 2021.

SOUZA, Sofia Branco. A 'comunidade académica' como um conceito errático. Sociologia: Revista do Departamento de Sociologia da FLUP, Porto, v. XX, p. 149-166, 2010. Disponível em: https://bit.ly/30nHWJw. Aceso em: 20 nov. 2021.

STOER, Stephen. Sociologia da Educação e formação de professores. Cadernos de Ciências Sociais, Porto, n. 6 , p. 75-90, 1988.

STOER, Stephen. El desarrollo de la sociología de la educación en Portugal. Educación y Sociedad, Havana, n. 7 , p. 7-28, 1990.

STOER, Stephen. Notas sobre o desenvolvimento da Sociologia da Educação em Portugal. Educação, Sociedade e Culturas, Porto, n. 26, p. 113-132, 2008. Disponível em: https://bit.ly/31YQt5O. Acesso em: 20 nov. 2021.

STOER, Stephen; AFONSO, Almerindo Janela. 25 anos de sociologia da educação em Portugal: Alguns percursos, problemáticas e perspectivas. Revista Crítica de Ciências Sociais, Coimbra, n. 52-53, p. 307-331, 1999. 